Article

\title{
Encapsulation and Characterization of Nanoemulsions Based on an Anti-oxidative Polymeric Amphiphile for Topical Apigenin Delivery
}

\author{
Tzung-Han Chou ${ }^{1, * \mathbb{D}}$, Daniel Setiyo Nugroho ${ }^{1}$, Jia-Yaw Chang ${ }^{2}$, Yu-Shen Cheng ${ }^{1}$, Chia-Hua Liang ${ }^{3}$ \\ and Ming-Jay Deng 4 (i)
}

check for updates

Citation: Chou, T.-H.; Nugroho, D.S.; Chang, J.-Y.; Cheng, Y.-S.; Liang, C.-H.; Deng, M.-J. Encapsulation and Characterization of Nanoemulsions Based on an Anti-oxidative Polymeric Amphiphile for Topical Apigenin Delivery. Polymers 2021, 13, 1016. https://doi.org/10.3390/ polym13071016

Academic Editor: Waldo M. Argüelles-Monal

Received: 28 February 2021

Accepted: 21 March 2021

Published: 25 March 2021

Publisher's Note: MDPI stays neutral with regard to jurisdictional claims in published maps and institutional affiliations.

Copyright: (c) 2021 by the authors. Licensee MDPI, Basel, Switzerland. This article is an open access article distributed under the terms and conditions of the Creative Commons Attribution (CC BY) license (https:/ / creativecommons.org/licenses/by/ $4.0 /)$.
1 Department of Chemical and Materials Engineering, National Yunlin University of Science and Technology, Yunlin 64022, Taiwan; danielsetiyanugraha@gmail.com (D.S.N.); yscheng@gemail.yuntech.edu.tw (Y.-S.C.)

2 Department of Chemical Engineering, National Taiwan University of Science and Technology, Taipei 10607, Taiwan; jychang@mail.ntust.edu.tw

3 Department of Cosmetic Science, Chia Nan University of Pharmacy and Science, Tainan 717, Taiwan; tinna_ling@mail.cnu.edu.tw

4 Department of Applied Chemistry, Providence University, 200 Taiwan Boulevard, Sec. 7, Taichung 43301, Taiwan; dengmj1020@pu.edu.tw

* Correspondence: chouth@yuntech.edu.tw; Tel.: +886-5534-2601 (ext. 4625); Fax: +886-5531-2071
Abstract: Apigenin (Apig) is used as a model drug due to its many beneficial bio-activities and therapeutic potentials. Nevertheless, its poor water solubility and low storage stability have limited its application feasibility on the pharmaceutical field. To address this issue, this study developed nanoemulsions (NEs) using an anti-oxidative polymeric amphiphile, $\mathrm{d}$ - $\alpha$-tocopheryl polyethylene glycol 1000 succinate (TPGS), hydrogenated soy lecithin (HL), black soldier fly larvae (BSFL) oil, and avocado (AV) oil through pre-homogenization and ultrasonication method. Addition of TPGS (weight ratios 100 and $50 \%$ as compared to HL) into NEs effectively reduced particle size and phase transition region area of NEs with pure HL. Incorporation of Apig into NEs made particle size increase and provided a disorder effect on intraparticle molecular packing. Nevertheless, the encapsulation efficiency of NEs for Apig approached to about 99\%. The chemical stability of Apig was significantly improved and its antioxidant ability was elevated by incorporation with BSFL oil and AV oil NEs, especially for NEs with single TPGS. NEs with single TPGS also exhibited the best Apig skin deposition. For future application of topical Apig delivery, NEs-gel was formed by the addition of hyaluronic acid (HA) into NEs. Their rheological characteristics were dominated by the surfactant ratios of HL to TPGS.

Keywords: Apigenin; encapsulation efficiency; nanoemulsions; TPGS; antioxidant ability; rheological characteristics

\section{Introduction}

Apigenin (Apig) is one of the natural dietary flavonoid compounds originating from the Apiaceae family [1], and it can be found in fruits, vegetables, and herbs [2]. Apig has been proven to play a potent role in biological activities such as effective wound healing [3], treatment for skin inflammation, and repairing UV-B-induced DNA damage in human skin [4]. However, Apig is classified as a BCS (Biopharmaceutical Classification System) II drug with low water solubility that hinders its bioavailability [5]. Thus, it becomes a big challenge to effectively penetrate Apig into skin layer.

To overcome the problem of drug solubility, different carriers such as ethosomes [6], nanoparticle [7], liposomes [8], and O/W emulsions [9] have been introduced to encapsulate Apig. Nevertheless, employing liposomes and ethosomes on drugs may induce unexpected side effects in humans $[10,11]$, and their protectional performances on the chemical stability of Apig are still not very clear. Among the delivery systems mentioned above, 
nanoemulsions (NEs) are a suitable vehicle for Apig because they exhibit high potential to improve the water solubility and bioavailability of several oil-soluble phytochemicals including quercetin [12], catechin [13], $\beta$-carotene [14], and emodin [15]. Furthermore, nanoemulsification is regarded as a promising strategy for promoting drug skin penetration without additional chemical enhances, where the nanoemulsion compositions (i.e., oils, surfactants, and co-surfactants) themselves can act as penetration enhancers on transdermal drug absorption [16]. NEs have been proven to increase drug deposition rate in skin [17] and to prolong the drug activity itself [18]. Therefore, the utilization of nanoemulsions is a good candidate for application of topical Apig delivery.

Usually, oils are considered as a structural core of NEs. Black soldier fly larvae (BSFL) oil and avocado (AV) oil are used herein to prepare NEs because both of them are able to form stable NEs in our previous works $[19,20]$. BSFL oil is a naturally occurring animal oil from black solder fly (Hermetia illucens) larvae. It possesses an antimicrobial activity against growth of Gram-negative bacteria, Gram-positive bacteria, and filamentous fungi [21], and it contains a high percentage of linoleic acid and oleic acid that can increase skin permeation [22]. AV oil is rich in omega fatty acids and shows many more pharmacological characteristics such as hypercholesterolemia management, cardiometabolic risk management, hypertension management, diabetes management, hepatoprotective effect, antimicrobial activity. Well refined AV oil may show a good skin penetration ability because it owns mono-unsaturated oleic acid [22]. To further enhance the thermodynamic stability and drug solubility of colloidal dispersions, binary surfactants are generally used [23,24]. D- $\alpha$-tocopheryl polyethylene glycol 1000 succinate (TPGS) and hydrogenated soy lecithin (HL) utilized as emulsifiers in NEs with Apig. TPGS is an amphiphilic derivative of natural vitamin $\mathrm{E}$ through esterification of vitamin $\mathrm{E}$ succinate, showing anti-oxidative characteristic. TPGS has been reported in various applications like, for example, as an anticancer agent [25], P-gp inhibitor [26], or additive in fabricating nanocarrier [27]. Hydrogenated soy lecithin (HL) shows negligible cytotoxicity effect and has been widely applied on preparation of liposomes [28] and as an emollient enhancer for lotion applications [29]. It can be expected that incorporation of TPGS and HL into NEs can provide antioxidant capacity and safety benefits on this Apig carrier.

Many studies have pointed that polymeric gelling agents are widely applied in the biomedical field [30], and they have pointed out the enhancement of drug percutaneous penetration in vitro and in vivo [31,32]. Hyaluronic acid (HA) one of polysaccharides known as a biological origin material, has excellent biocompatibility, non-immunogenicity, and biodegradability, which make it suitable for medical applications [33]. Besides, it has been confirmed that HA could not only control drug release but also improve transdermal absorption performance [34]. Herein, NEs gels were developed by incorporated NEs with HA for future topical Apig application. The rheological characteristics of gels would affect the drug release behavior and interaction time of drug with skin, and those played a key role in determination of transdermal drug absorption [35]. Therefore, rheological characteristics of these HA-NEs gels were measured in this work.

In this study, BSFL oil- and AV oil- NEs with various formulation compositions for encapsulation of Apig were manufactured by pre-homogenization combined with an ultrasonication way, and their physicochemical characteristics and drug encapsulation were determined. The effects of surfactant ratios of HL to TPGS on morphological observation, size, zeta potential, phase transition behavior, encapsulation performance, and chemical stability of BSFL oil and AV oil NEs loaded with Apig were investigated comprehensively. The antioxidant capacity and skin deposition amount of Apig of these NEs varied with different mixed surfactant ratios were also examined. Additionally, BSFL oil and AV oil NEs-HA gels were fabricated and their rheological properties were investigated deeply. This study hopes to provide useful information on the development of Apig-loaded carriers for topical delivery. 


\section{Materials and Methods}

\subsection{Materials}

BSFL oil was provided by Wormax Inc, Taiwan. AV oil was purchased from Storino's Quality Product( Glendale, Arizona, USA). TPGS was purchased from Eastman( South Wales, UK). HL was supplied from Merck KGaA(Darmstadt, Germany). Uranyl acetate was purchase from Electron Microscopy Science(Hatfield, Britain). Apig (5,7-dihydroxy-2-(4hydroxyphenyl)-4H-1-benzopyran-4-one) was purchased from Tokyo Chemical Company CO., LTD.(Tokyo, Japan). Hyaluronic Acid was purchased from Bloomage Freda Biopharma co., LTD., Taiwan. Methanol was purchased from Avantor Performance Materials Inc. (Radnor Township, Pennsylvania, USA). Ethanol was purchase from Echo Chemical CO., LTD., Taiwan. Sodium chloride was purchased from Showa Chemical CO., LTD., (Tokyo, Japan). Artificial skin membrane was purchased from Merck Millipore Ltd., Co Cork, Ireland. Ultra-pure water produced by a Mill-Q-plus purification instrument (Burlington, Massachusetts, USA) was used for all experiments.

\subsection{Preparation of NEs and Apig Loaded NEs}

The previous process [20] with some modification was adopted to prepare BSFL oil and AV oil NEs. Briefly, oils, surfactants and aqueous phase were pre-heating in $80^{\circ} \mathrm{C}$ in $10 \mathrm{~min}$ then homogenized at 15,000 rpm for 2 min using D-500 homogenizer (Wiggen Hausser, Germany). Further, the emulsified dispersion was sonicated under a power of $80 \mathrm{~W}$ at $45^{\circ} \mathrm{C}$ for $30 \mathrm{~min}$ with an ultra-sonicator (Misonix 3000,Farmingdale, New York, USA). $10 \mathrm{~mL}$ of blank NEs was prepared by oil content $1 \%$, the emulsifier consisted of surfactant to oil ratio (SOR) 60\%, and surfactant ratio of HL/TPGS at 0/100, 50/50, and 100/0. The Apig loaded NEs were prepared using the same procedure as described above with addition of $2 \mathrm{mg}$ Apig in the oil phase followed with stirring using vortex mixer. Each formulation repeated at least three times.

\subsection{Transmission Electron Microscopy (TEM) Characteristics}

Morphological characteristics of NEs were analyzed using a transmission electron microscope (HITACHI H-7500, Tokyo, Japan) at $100 \mathrm{kV}$. Before each TEM experiment, $5 \mu \mathrm{L}$ of NEs was spread on the copper grid coated with carbon for $10 \mathrm{~min}$ and then negatively stained with $2 \mu$ ll of uranyl acetate solution $(2.5 \%, w / w)$. The sample was kept for $3 \mathrm{~min}$ at room temperature and subsequently remained in an electronic dried box before observation.

\subsection{Droplet size, PdI, Zeta Potential Measurement, and Physical Stability Analysis}

Average particle size (APS) and polydispersity index (PdI) were determined using Zeta Plus Analyzer (Brookhaven Instruments Corporation, Holtsville, NY, USA) and followed by zeta potential measurement. Fresh empty NEs and Apig-loaded NEs were pipetted $1 \mathrm{~mL}$ and appropriately diluted in pure water to reach the test criteria. Hydrodynamic particle size and polydispersity index were obtained by $10 \mathrm{~min}$ of automatic cycle calculation and the zeta potential was measured by phase analysis light scattering combined with electrophoresis technique. At least three independent measurements were performed for each sample and reported as the mean \pm standard deviation. Besides, the storage stable days of NEs at $24.5^{\circ} \mathrm{C}$ were determined by average particle size (APS) $<500 \mathrm{~nm}$, polydispersity (PdI) $<0.4$, or no phase separation through optical observation.

\subsection{Thermal Phase Change Behavior of NEs}

Thermal phase transition behavior of NEs were determined using differential scanning calorimetry (DSC) (DSC 1 instrument with the STARe system, Mettler Toledo Inc., Greifensee, Switzerland), controlled by a Huber TC45 immersion cooler. Approximately $20 \mu \mathrm{L}$ samples were placed in aluminum sealed pans, while $20 \mu \mathrm{L}$ water-sealed pans used as a reference. The pans were placed in the DSC chamber with an initial temperature of $25^{\circ} \mathrm{C}$. The thermal analysis was carried out over a temperature range of $-10^{\circ} \mathrm{C}$ 
to $80^{\circ} \mathrm{C}$ with $5^{\circ} \mathrm{C} / \mathrm{min}$ heating-cooling rate in $\mathrm{N}_{2}$ gas. All samples were analyzed with three heating-cooling cycles and repeated in triplicate $(n=3)$.

\subsection{Encapsulation Characteristics of NEs for Apig}

Apig amounts loaded into NEs were assayed by HPLC instrument. The encapsulation efficiency (EE) and loading efficiency (LE) of NEs were calculated through the following equations:

$$
\begin{gathered}
\text { EE }(\%)=(\text { total drug amount }- \text { free drug amount }) / \text { total drug amount } \times 100 \% \\
\text { LE }(\%)=(\text { total drug amount }- \text { free drug amount }) / \text { total oil amount } \times 100 \%
\end{gathered}
$$

In brief, HPLC apparatus equipped with a model L-2200 autosampler, L-2130 pump, L-2455 diode array detector, and a temperature controller. The column of Luna ${ }^{\circledR} 5 \mu \mathrm{m}$ C18(2) $100 \AA$ was used and pure methanol as the mobile phase flow at a flow rate of $1.0 \mathrm{~mL} / \mathrm{min}$. The temperature set to be $35^{\circ} \mathrm{C}$ and the detection wave number ranged from $200 \mathrm{~nm}$ to $700 \mathrm{~nm}$ was used and specific Apig wavenumber at $267 \mathrm{~nm}$ was marked. Every sample was filtered through a PVDF 0,22 $\mu \mathrm{m}$ (Milipore Millex-GV) filter. The free Apig content was determined by measuring the amount of untrapped Apig in the aqueous phase after ultrafiltration centrifugation of NEs at 15000rpm and $4{ }^{\circ} \mathrm{C}$ for $2 \mathrm{hr}$ with a $5 \mathrm{~K}$ MWCO column (Vivaspin, GE healthcare) placed on an Eppendorf Centrifuge 5424 R.

\subsection{Chemical Stability Analysis}

The chemical stabilities of pure Apig dispersion and Apig-loaded NEs were investigated by using a UV-Vis spectrophotometer (SPECTROstar ${ }^{\circledR}$ Nano BMG LABTECH GmdH, Ortenberg, Germany). The study was done by comparing the sample absorbance with methanolic Apig solution (5\% v/v methanol). Absorbance wavelengths at $267 \mathrm{~nm}$ and $336 \mathrm{~nm}$ were measured in the $0,1,2,3,4,6,12,18,24,30,36 \mathrm{~h}$.

\subsection{Antioxidant Activity Assay}

The antioxidant activities of pure Apig dispersion, NEs encapsulated with Apig, were determined by using free radical-screening activities of DPPH assay, and the method was based on previous report [36] with some modifications. $0.024 \mathrm{~g} / \mathrm{L}$ of DPPH solution was prepared and then reacted with samples including Apig and the Apig-loaded NEs. $0.1 \mathrm{~mL}$ of the samples were added to $1.9 \mathrm{~mL}$ of the DPPH solutions and kept in the dark place. Sampling was done for each $10 \mathrm{~min}$ in the period of $40 \mathrm{~min}$ and their absorbance values were measured at $517 \mathrm{~nm}$ with a UV-Vis spectrophotometer. Thus, the percentage inhibition on DPPH free radical activity (\% inhibition) was calculated using equation below:

$$
\% \text { inhibition }=\left(\frac{A B S_{\text {control }}-A B S_{\text {sample }}}{A B S_{\text {control }}}\right) \times 100
$$

Where, $A B S_{\text {control }}$ is the absorption value of control DPPH and $A B S_{\text {sample }}$ is the absorption value of reacted $\mathrm{DPPH}$.

\subsection{Drug Penetration Study}

A skin drug penetration of Apig-loaded NEs was determined using a Franz diffusion cell through artificial skin Strat- $\mathrm{M}^{\circledR}$ Membrane $25 \mathrm{~mm}$ discs. The receptor compartment was filled with medium contained $40 \%$ ethanol and $0.9 \% \mathrm{NaCl}$. Volume of $5 \mathrm{~mL}$ medium was added ad maintained at $37^{\circ} \mathrm{C}$ by circulating bath with a small magnetic stirrer was placed in the receptor chamber and set the speed at $700 \mathrm{rpm}$. The artificial skin was use directly without any pretreatment and fitted to the diffusion cell. $1 \mathrm{~mL}$ of prepared NEs then added to the top compartment. Using HPLC at 1, 2, 3, 6, 10, 16, 24-h, $0.5 \mathrm{~mL}$ of receptor medium was withdrawn and analyzed. To further analyze the Apig deposition on the artificial skin, the membrane was removed from the Franz cell and cleaned using a paper wipe. Next, the membrane was cut into small pieces and put into a bottle with 
methanol and ultrasonicated for $20 \mathrm{~min}$. Before HPLC analysis, the sample was centrifuge at $2000 \mathrm{rpm}$ for $15 \mathrm{~min}$ and filtered through $0.22 \mu \mathrm{m}$ filter.

\subsection{Preparation of NEs-HA Gels}

Before incorporation of HA with NEs, blank NEs with SOR $=30$ and $60 \%$ and surfactant ratios of HL to TPGS $=0 / 100,50 / 50$, and 100/0 were prepared as described early. Three and six percent $w / w$ of hyaluronic acid in blank NEs were scaled and added to the NE samples. Then, a vortex mixer was used to strongly disperse HA into the NEs. To ensure complete dispersion of HA, the rotary-mixer equipment was introduced for every sample for $60 \mathrm{~min}$. Finally, the vacuum instrument was used to remove the bubble from the NEs-HA gels for avoiding evade void effect on rheology measurement.

\subsection{Rheology Study}

Rheological investigation was performed by HR-2 Discovery Hybrid Rheometer (DHR) TA instrument, equipped with a plate geometry $(40 \mathrm{~mm}$ with temperature-controlled base). To investigate the rheological behavior, different hyaluronic concentration ( $3 \%$ and $6 \%, w / w)$ was added to NEs as mentioned above. Before the rheological analysis, the stability tests of NEs (Figures S1 and S2 in the Supplementary Information) were carried through a modified method as reported elsewhere [37,38]. Then, linear viscoelastic (LVE) region was measured by amplitude sweep and followed with frequency sweep test. Several presumptions were applied such as $25{ }^{\circ} \mathrm{C}$ observation temperature, $0.1-100 \mathrm{rad} / \mathrm{s}$ for frequency sweep radian range, and 15 sampling point per decades. After HA incorporated into NEs, the storage modulus $\left(G^{\prime}\right)$ and loss modulus $\left(G^{\prime \prime}\right)$ as a function of strain rate and frequency were measured.

\subsection{Statistical Analysis}

In this work, all experiments were repeated at least three times and the data were represented as the mean value \pm standard deviation. The results were statistically analyzed by ANOVA test and $p$ values $<0.05$ were considered as significant.

\section{Results and Discussion}

\subsection{Morphology Assay}

Morphological appearance of nanosized colloids as well as their size was studied under a microscopy analysis. TEM images of Apig loaded AV-NEs and BSFL-NEs are shown in Figure 1. Spherical droplets were observed in the studied sample. The comparations of average particle size determined from the TEM images and DLS measurement showed no significant difference. The pictures also confirmed the possible existence of micelle in the dispersion indicated with the presence of particles with diameter under $10 \mathrm{~nm}$. The droplets ware distributed moderately homogeneous throughout the formulations with slight aggregation observed in several dispersion systems. These observations also indicated that the Apig-loaded nanoemulsion was fabricated successfully.

In addition, the result suggested that using TPGS as a standalone surfactant would exhibit an aggregation phenomenon where the small particle diffusing to the larger particle. In colloidal systems, this situation can be caused by the solubility of a droplet increases notably as its radius becomes smaller [39]. An interesting finding was shown in the mixed surfactant system, where aggregation phenomena was eliminated and each particle has a better dispersive characteristic. This behavior may attribute to the increasing absolute zeta potential value by the addition of HL and decreasing the number of PEG which decreases the dispersion solubility in water [40]. 

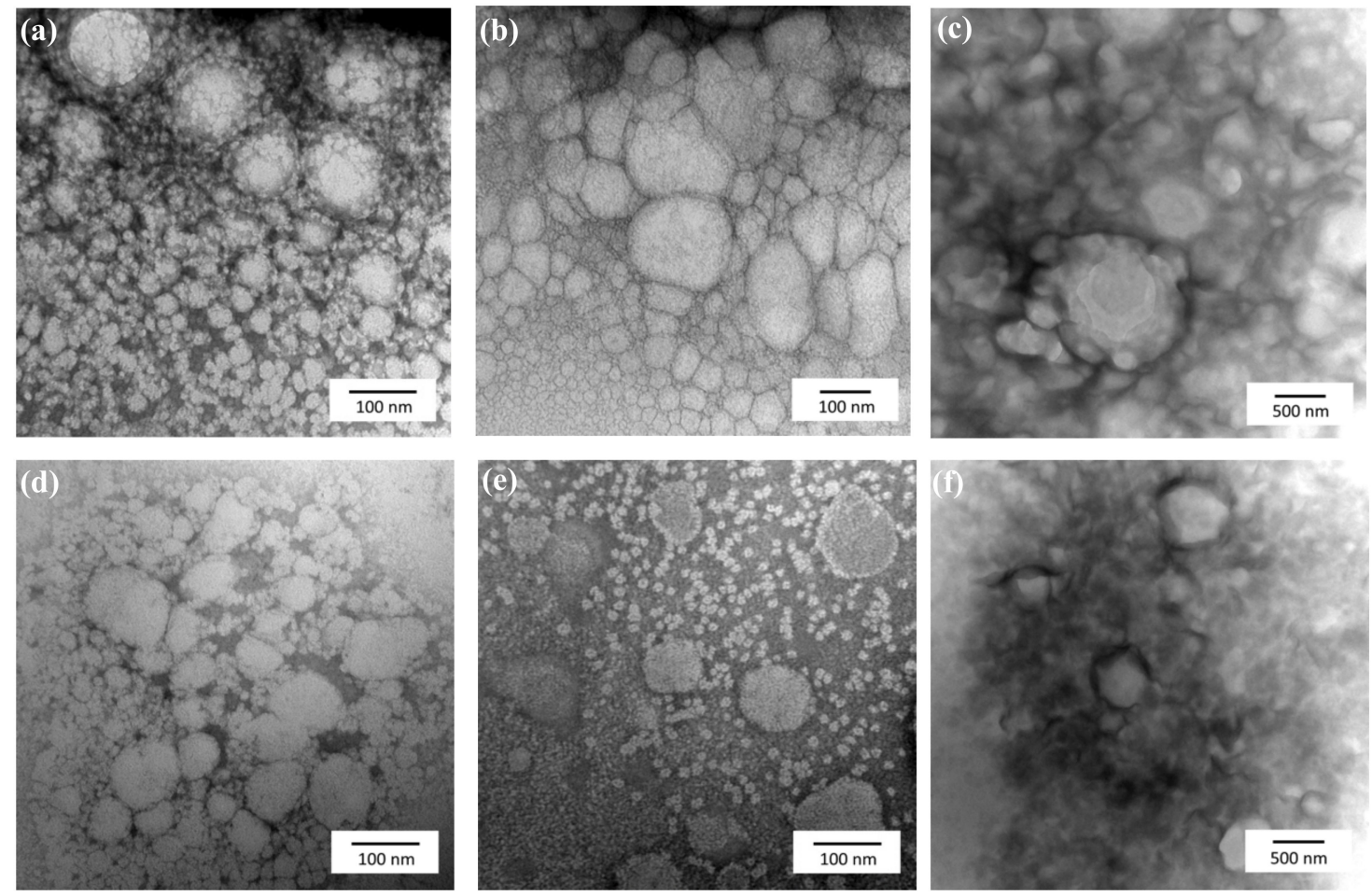

Figure 1. TEM images of Apig incorporated into BSFL oil NEs with SOR $60 \%$, oil content $1 \%$, and surfactant ratios of HL/TPGS $=$ (a) 0/100, (b) 50/50, and (c) 100/0. TEM images of Apig incorporated into AV oil NEs with the same composition ratios as described above as surfactant ratios of HL/TPGS = (d) 0/100, (e) 50/50, (f) 100/0.

\subsection{DLS Characterization and PHYSCIAL Stability of Nanoemulsions Encapsulated with Apig}

The average particle size, polydispersity, and zeta potential of BSFL oil and AV oil NEs are listed in Table 1. The average particle size of NEs added with TPGS (weight ratios 100 and $50 \%$ as compared to HL) were quite smaller than those prepared with only HL. Similarly, other works found that addition of TPGS to the colloidal system could decrease the particle size and increase its stability $[36,41]$. However, the BSFL oil NEs were found to be slightly smaller in size than the AV oil NEs, which was probably affected by the higher content of saturated fatty acid in BSFL oil. It can be seen that the particle sizes of AV oil NEs or BSFL NEs with pure TPGS systems increase triplicate from before to after Apig encapsulation. However, an increased degree on the size of NEs decreased with increasing HL amount, while the PdI shifted inconsistency and the ZP value increased for all formulation. This finding suggested that the Apig successfully was encapsulated into the AV oil NEs or BSFL NEs. The infusion of Apig into the particles cost the multiplication in the particle size and increasing the zeta potential. In addition, it might be that the Apig was not completely soluble in the oil phase or that the Apig solubility in oil was over its saturation point.

Additionally, Table 1 shows that the number of stable days for BSFL oil and AV oil NEs with the addition of TPGS is much higher than those without TPGS, no matter before or after Apig encapsulation. This might be because the PEG side chains of TPGS can provide a steric effect between NEs and a downsizing effect of TPGS on NEs may increase their surface charge density (possibly enhancing the electrostatic repulsion between NEs). Such similar TPGS effects on other colloidal systems were also reported elsewhere [36,42]. However, one could find that the storage stability of NEs incorporated with Apig was lower than those without Apig. This indicated that Apig might give a strong disturbed effect on the intra-NEs molecular packing, resulting in the low storage stability of NEs. 
Table 1. Encapsulation efficiency and loading efficiency of BSFL oil NEs and AV oil NEs with SOR $60 \%$, oil content $1 \%$ and surfactant ratios of HL/TPGS for Apig with their average particle size (APS) $\mathrm{nm}$, polydispersity (PdI), zeta potential (ZP) $\mathrm{mV}$, and stable days (SD) by comparison before with after encapsulation.

\begin{tabular}{|c|c|c|c|c|c|c|}
\hline Oil & HL/TPGS & & $\begin{array}{c}\text { Before } \\
\text { Encapsulation }\end{array}$ & $\begin{array}{c}\text { After } \\
\text { Encapsulation }\end{array}$ & EE (\%) & LE (\%) \\
\hline BSFL oil & $0 / 100$ & $\begin{array}{l}\text { APS: } \\
\text { PdI: } \\
\text { ZP : } \\
\text { SD: }\end{array}$ & $\begin{array}{c}32.13 \pm 0.83 \\
0.19 \pm 0.01 \\
-22.2 \pm 0.4 \\
210 \pm 7\end{array}$ & $\begin{array}{c}135.5 \pm 10.9 \\
0.21 \pm 0.02 \\
-35.1 \pm 5.9 \\
45 \pm 3\end{array}$ & $99.72 \pm 0.01$ & $1.994 \pm 0.02$ \\
\hline \multirow{5}{*}{ AV oil } & $50 / 50$ & $\begin{array}{l}\text { APS: } \\
\text { PdI: } \\
\text { ZP : } \\
\text { SD: }\end{array}$ & $\begin{array}{c}51.20 \pm 3.36 \\
0.35 \pm 0.01 \\
-41.9 \pm 0.8 \\
200 \pm 7\end{array}$ & $\begin{array}{c}122.1 \pm 7.9 \\
0.26 \pm 0.04 \\
-51.5 \pm 6.4 \\
30 \pm 2\end{array}$ & $99.69 \pm 0.01$ & $1.993 \pm 0.02$ \\
\hline & $100 / 0$ & $\begin{array}{l}\text { APS: } \\
\text { PdI: } \\
\text { ZP: } \\
\text { SD: }\end{array}$ & $\begin{array}{c}195.20 \pm 0.80 \\
0.16 \pm 0.02 \\
-43.0 \pm 0.7 \\
5 \pm 1\end{array}$ & $\begin{array}{c}230.4 \pm 13.0 \\
0.24 \pm 0.01 \\
-65.8 \pm 3.6 \\
3 \pm 1\end{array}$ & $99.39 \pm 0.01$ & $1.987 \pm 0.03$ \\
\hline & $0 / 100$ & $\begin{array}{l}\text { APS: } \\
\text { PdI: } \\
\text { ZP : } \\
\text { SD: } \\
\text { APS: }\end{array}$ & $\begin{array}{c}32.80 \pm 3.54 \\
0.19 \pm 0.08 \\
-13.1 \pm 0,02 \\
346 \pm 10 \\
48.76 \pm 9.75\end{array}$ & $\begin{array}{c}120.1 \pm 8.8 \\
0.21 \pm 0.03 \\
-30.1 \pm 1.7 \\
56 \pm 4 \\
118.39 \pm 2,6\end{array}$ & $99.64 \pm 0.05$ & $1.99 \pm 0.11$ \\
\hline & $50 / 50$ & $\begin{array}{l}\text { PdI: } \\
\text { ZP : } \\
\text { SD: }\end{array}$ & $\begin{array}{c}0.33 \pm 0.02 \\
-41.2 \pm 0.6 \\
300 \pm 7\end{array}$ & $\begin{array}{c}0.25 \pm 0.03 \\
-43.3 \pm 4.1 \\
40 \pm 3\end{array}$ & $99.81 \pm 0.01$ & $1.99 \pm 0.02$ \\
\hline & $100 / 0$ & $\begin{array}{l}\text { APS: } \\
\text { PdI: } \\
\text { ZP : } \\
\text { SD: }\end{array}$ & $\begin{array}{c}231.8 \pm 4.2 \\
0.20 \pm 0.03 \\
-50.1 \pm 1.64 \\
9 \pm 1\end{array}$ & $\begin{array}{c}234.7 \pm 7.31 \\
0.19 \pm 0.01 \\
-63.6 \pm 2.2 \\
5 \pm 1\end{array}$ & $99.74 \pm 0.09$ & $1.99 \pm 0.18$ \\
\hline
\end{tabular}

\subsection{Endothermic Phase Change Behavior}

Influences of TPGS content and Apig on the endothermic phase change behavior of AV oil and BSFL oil NEs were determined by DSC. Figure 2 shows endothermic DSC curves of AV oil- and BSFL oil- NEs with different surfactant ratios of HL to TPGS at SOR $60 \%$ and oil $1 \%$. Single phase transition region was found in the temperature range of $56-68^{\circ} \mathrm{C}$ for the $\mathrm{AV}$ oil NEs (marked by $\mathrm{P} 2$ region), whereas two phase transition regions of -4 to $37^{\circ} \mathrm{C}$ (marked by P1 region) and $56-68^{\circ} \mathrm{C}$ (P2) were obtained for BSFL oil NEs. According to previous reports $[16,20], \mathrm{P} 1$ and P2 are associated with BSFL oil and pure HL dispersions, respectively. At fixed oil content and SOR, one can find that the peak size of P1 or P2 region decreases with increasing TPGS ratio. Also, the enthalpy change of P1 or P2 region decreases with increasing TPGS content (Table 2). This effect may account for the fact that TPGS would provide a steric effect on the molecular packing within the dispersion core. A similar effect of TPGS on molecular arrange of micelle systems is also reported elsewhere [41]. While there was no observed transition for AV oil and BSFL oil NEs, an other report considered a completely soluble TPGS in a mixture of water and oil [43]. Moreover, after incorporations of Apig to the NEs system, the transition areas for all regions were consistently decrease by comparison with the DSC results reported previously $[14,15]$. This may cause by an increase in intermolecular interactions between Apig and TPGS/HL oils in a compacted structure, resulting in the occurrence of disordered molecular packing. In the other hand, the transition shape became broader after Apig encapsulation which might induce an increase of particle size and less homogeneous size distribution. These results can also be supported by the other literature [44], where a long-range order crystal structure of lycopene disappeared after it was encapsulated into NEs. 


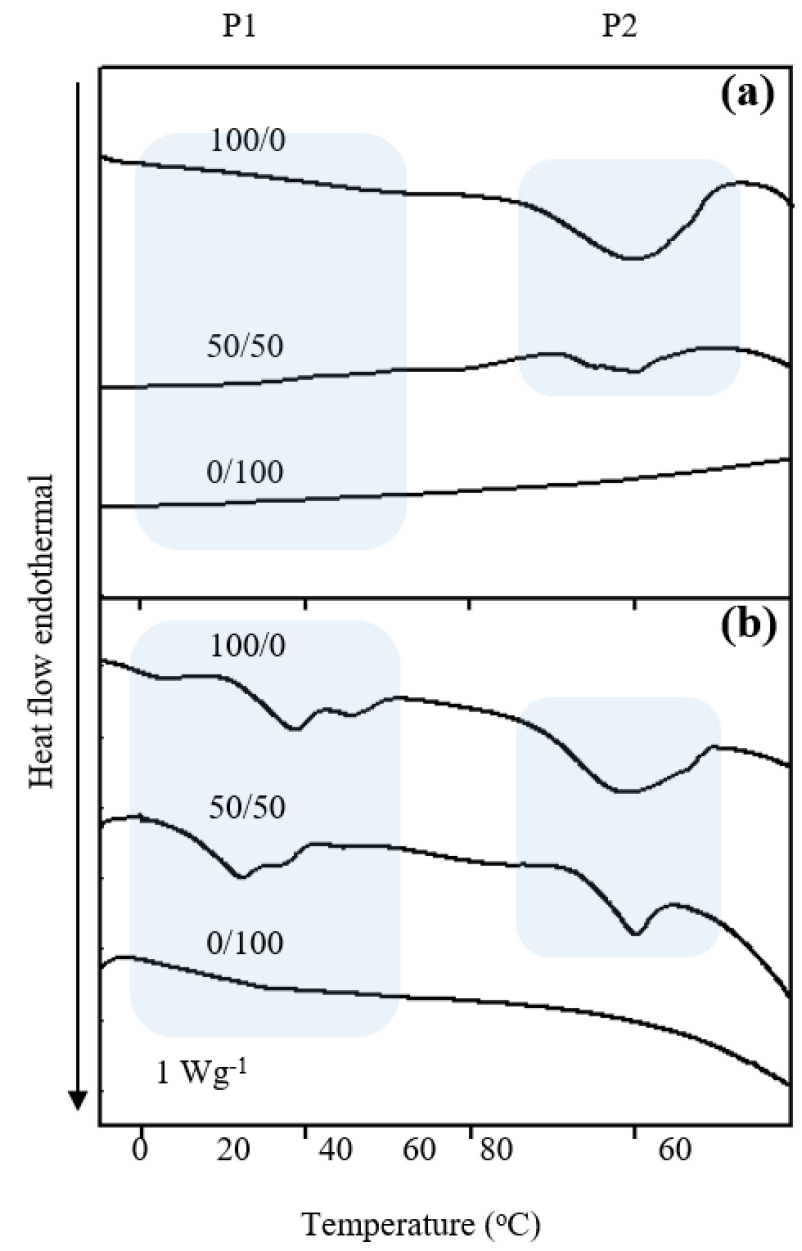

Figure 2. Effects of surfactant ratio of HL/TPGS on endothermal DSC diagrams of (a) AV oil NEs and (b) BSFL-NEs encapsulated with Apig at SOR 60\% and oil 1\%.

Table 2. Enthalpy changes $(\Delta \mathrm{H})$, main transition temperature $(\Delta \mathrm{Tm})$, and half-width transition temperature $\left(\Delta \mathrm{T}_{1 / 2}\right)$ of BSFL oil and AV oil nanoemulsions encapsulated with Apig under SOR $=60 \%$ and different surfactant ratios of HL/TPGS on P1 and P2 phase transition regions obtained from endothermal DSC curves.

\begin{tabular}{|c|c|c|c|c|c|c|c|}
\hline Oil & HL/TPGS & $\operatorname{Tm}{ }^{p 1}$ & $\operatorname{Tm}{ }^{p 2}$ & $\begin{array}{c}\Delta H^{p 1} \\
(\mathrm{~mJ})\end{array}$ & $\begin{array}{c}\Delta H^{p^{2}} \\
(\mathrm{~mJ})\end{array}$ & $\Delta \mathrm{T}_{1 / 2} \mathrm{p}^{\mathrm{1}}$ & $\Delta \mathrm{T}_{1 / 2} \mathrm{p}^{2}$ \\
\hline \multirow[t]{3}{*}{ BSFL oil } & $0 / 100$ & 14.65 & - & 0.95 & - & 4.83 & - \\
\hline & $50 / 50$ & 12.13 & 60.05 & 4.48 & 2.05 & 4.81 & 2.37 \\
\hline & $100 / 0$ & 18.84 & 60,41 & 5.77 & 8.82 & 3.39 & 5.75 \\
\hline \multirow[t]{3}{*}{ AV oil } & $0 / 100$ & & - & & - & & - \\
\hline & $50 / 50$ & & 59.91 & & 2.58 & & 5.19 \\
\hline & $100 / 0$ & & 59.48 & & 11.78 & & 7.44 \\
\hline
\end{tabular}

-: Data cannot be determined.

\subsection{Encapsulation Performance of Apig}

The encapsulation efficiency (EE) and loading efficiency (LE) of BSFL oil and AV oil NEs with different surfactant ratios of HL/TPGS (0/100, 50/50, and 100/0) have been determined as listed in Table 1. One can find that the EE and LE of BSFL oil and AV oil NEs for Apig approached to about $99 \%$ and $1.99 \%$ for all formulations, respectively. It was confirmed that the Apig encapsulation was handled with optimally under nanoemulsion preparation. One can see that the free Apig was less than $1 \%$ which is in a row with the 
nature of low solubility of Apig in water. Besides, high energy preparation method would provide sufficient energy to generate high sear stress which could rupture the viscous droplets and facilitate the emulsifications [45]. Different oils and surfactant ratios would not affect the EE and LE, where it provided an opportunity to increase the drug loading in the system. Besides that, it could be suggested that the Apig was well-interacted with TPGS, HL, and oils, where one could not find any bulk phase separation or drug dissoluble peak in DSC curves.

\subsection{Chemical Stability Analysis of Apig Loaded into Nanoemulsions}

To determine whether AV oil NEs and BSFL oil NEs can protect the chemical activity of Apig, their impacts on chemical degradation during room temperature storage were monitored. The percentage of remaining Apig concentration during storage is measured with certain intervals of time as shown in Figure 3. As a pure Apig solution in 5\% methanol, its concentration percentage quickly decayed to $40 \%$ at the first $12 \mathrm{~h}$ and remained constant until $36 \mathrm{~h}$. The occurrence of chemical degradation activity of Apig was found, possibly resulting from Apig oxidation in the environment of abundant water and air.

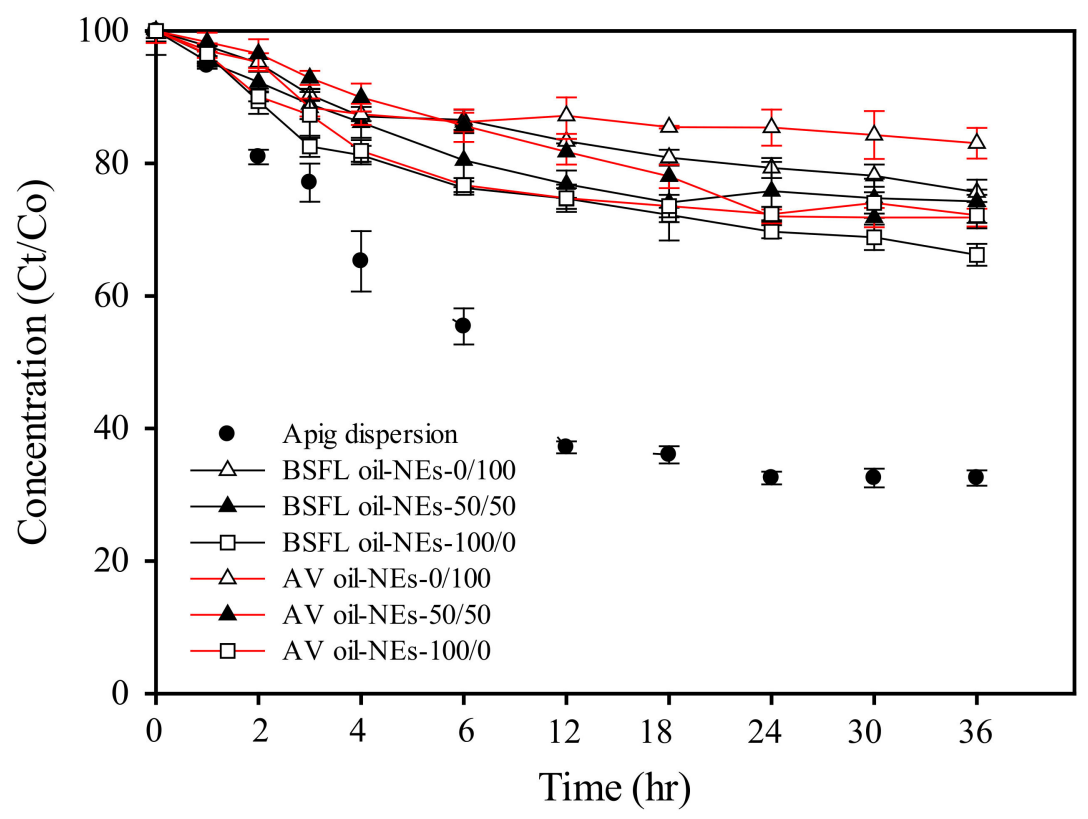

Figure 3. Chemical storage stability of Apig incorporated into BSFL oil NEs and AV oil NEs with SOR $60 \%$, oil content $1 \%$, and different surfactant ratios of HL to TPGS.

On the other hand, incorporation of Apig into the NEs greatly enhanced its chemical stability up to $>84 \%$ after $36 \mathrm{~h}$ in the TPGS mediated AV oil NEs. The Apig degradation then seemed faster at the initial stage and relatively remained constant after $6 \mathrm{~h}$. BSFL oil NE using HL as standalone surfactant showed lower remaining chemical stability of Apig (approximately 73\% compared as the initial concentration), while utilization of mixed surfactants (HL/TPGS) maintained at $76 \%$ for BSFL oil NEs. Similar effect of TPGS content on the protection ability of Apig was also found in AV oil NEs. TPGS has an $\alpha$-tocopheryl structure which may provide an antioxidant activity [46]. The result suggested that incorporation of Apig into BSFL oil and AV oil NEs could avoid Apig quickly degradation. Besides, the degradations rate of Apig was related with the droplet size of both NEs by compared with the results of DLS. Such a similar finding was also reported on Apig encapsulation in ethyl oleate $\mathrm{O} / \mathrm{W}$ emulsions [9]. It has been reported that larger droplets surface possibly induced higher diffusion of Apig across the interface, resulting in Apig degradation. 


\subsection{Antioxidant Ability Assay}

The antioxidant activities of Apig, blank NEs and NEs encapsulated with Apig were determined by the DPPH radical sequestration method, as shown in Figure 4. The blank BSFL oil NEs presented an antioxidant activity ranged from 6.4 to $9.3 \%$, while empty AV oil NEs have a lightly lower inhibition percentage ranged from 4.1 to $7.5 \%$. With increasing TPGS content in blank NEs and Apig-lead NEs, their antioxidant activities were elevated. Such enhanced effect of TPGS on antioxidant activity of NEs could be supported by the finding in the Section 3.6. Furthermore, BSFL oil NEs with or without Apig showed slightly higher antioxidant activity than AV oil NEs. This may attribute to the fact that AV oil used herein was refined oil in which the value of radical scavenging activity was reduced. This inference was able to be supported by the other study [47], which found that refining process could decrease the antioxidant activity through eliminating minor constituents such as phenols, oryzanol, phytosterols and tocopherol.

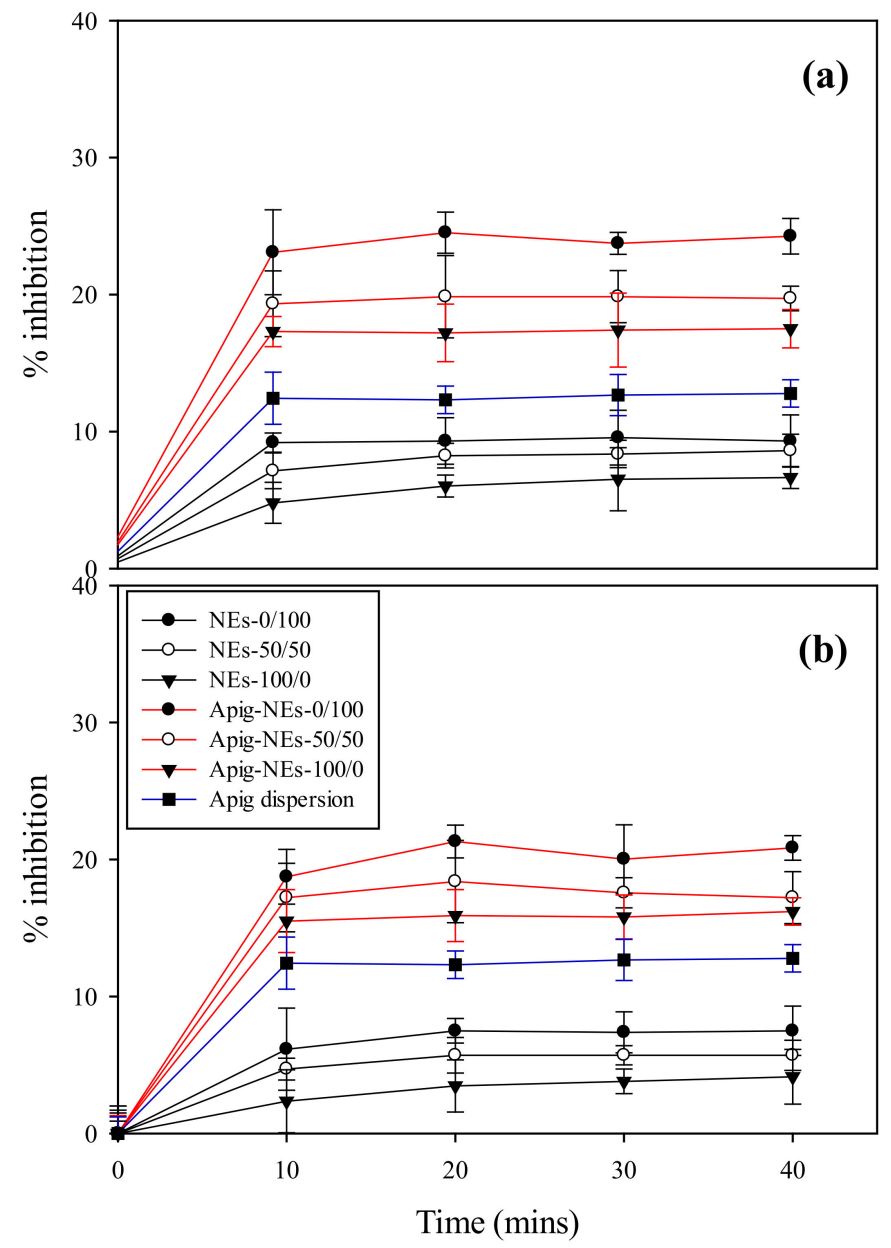

Figure 4. Antioxidant activities of Apig, blank NEs, and Apig loaded (a) BSFL oil NEs and (b) AV oil NEs with different surfactant ratios of HL/TPGS at SOR $60 \%$ and oil content $1 \%$.

\subsection{Artificial Skin Deposition of NEs Encapsulated with Apig}

The drug penetration ability of NEs in the skin generally was influenced by drug solubility nature and the formulation composition. Franz diffusion cell assay with artificial skin membrane was performed to evaluate the skin permeation/retention ability of Apigloaded NEs. Because Apig content cannot be detected in the receptor medium, the only skin deposition of Apig-loaded BSFL oil NEs and AV oil NEs with different surfactant ratios of HL/TPGS is shown in Figure 5, whatever the formulation. It was shown that AV oil NEs performed a similar permeated drug percentage as BSFL oil NEs with a fixed surfactant. 
However, an increase in the TPGS content promoted Apig deposition percentage in the skin membrane for BSFL oil and AV oil NEs. This might be attributed to the downsize effect of NEs by addition of TPGS. In addition, an other study reported that the colloidal size played a key role in dermal drug delivery [48].

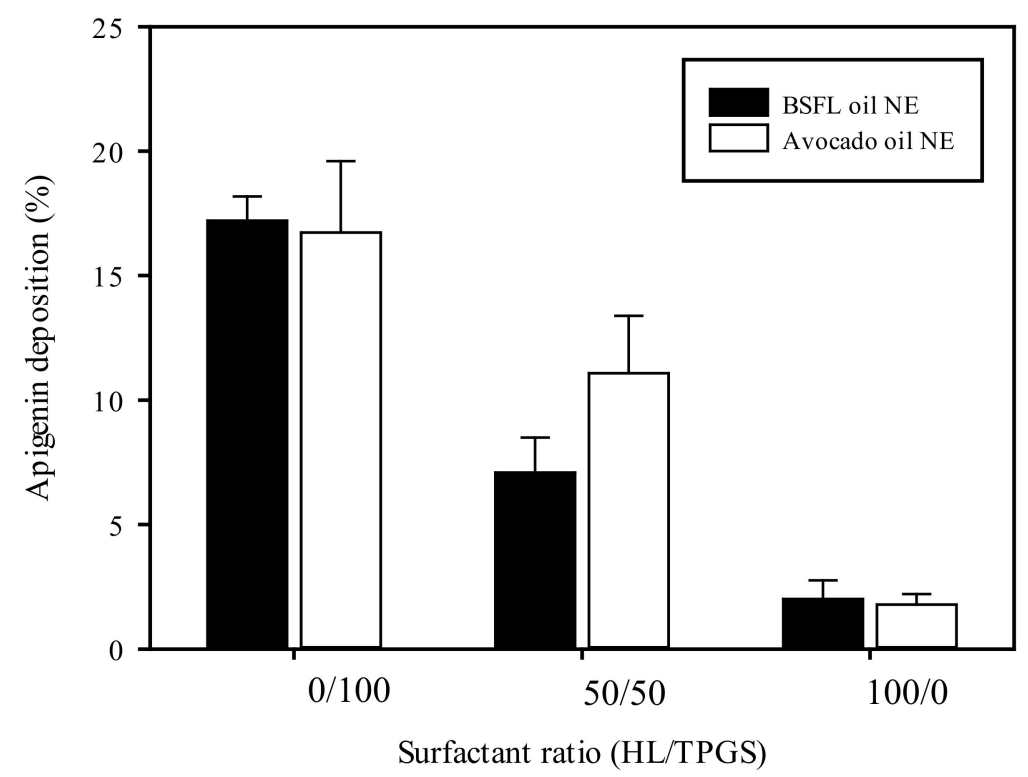

Figure 5. Artificial skin deposition of Apig loaded BSFL oil NEs and AV oil NEs with different surfactant ratios of HL/TPGS at SOR $60 \%$ and oil content $1 \%$.

\subsection{Rheology Behavior of Nanoemulsions in HA Gel}

The spreadability of topical formulations is highly related to their rheological behavior. Figures 6 and 7 illustrate the frequency-dependence of $G^{\prime}$ and G" of BSFL oil and AV oil NEs with HA gels, respectively, under a constant oscillation strain of $1 \%$. One can see that the rheological behavior of NEs-HA gels was significantly impacted by different surfactant ratios of HL to TPGS impact rather than HA concentration or SOR for both BSFL and AV oils NEs. As addition of pure TPGS with NEs in a fixed $6 \%$ of HA, increasing SOR from $30 \%$ to $60 \%$ will slightly decrease the crossover modulus point and increasing the $G^{\prime}$ value, which may be related to a decrease in the surface tension. This similar phenomenon was reported elsewhere, in which an increase in dispersant concentration would lead to an increase on $\mathrm{G}^{\prime}$ value of the gel formulations [49].

NEs with pure HL in HA gels exhibited an elastic behavior, where G' exceeded G" over the entire frequency range, indicating the formation of a gel-like substance. This behavior was probably caused by weak repulsive interaction between HA and surface of NEs-HL. However, NEs added with mixed surfactants of HL/TPGS $=50 / 50$ in HA gels expressed $G^{\prime \prime}>G^{\prime}$ over the entire frequency, reflecting their viscous nature. Their $G^{\prime}$ values initially increased but had a sharp downturn at a certain high frequency, suggesting that there might be an occurrence of network rupture with loss of elasticity. This implied that HL/TPGS (50/50) cosurfactants would produce strong repulsive interaction between HA network and NEs, possibly inducing a phase separation. Additionally, NEs with pure TPGS in HA gels were viscoelastic samples, where the elastic $\left(G^{\prime}\right)$ and viscous $\left(G^{\prime \prime}\right)$ moduli of the sample crossed at a certain frequency, implying a relaxation time. The magnitudes of both $G^{\prime}$ and $G^{\prime \prime}$ were increased; however, the moduli expressed a strong frequency dependence. This rheological characteristic was very different from that of NEs with the addition of HL in HA gels. Particularly, there is no plateau in $G^{\prime}$ at long timescales, implying the samples were able to relax. Their rheology was indicative of a transient network formed by junction at a finite time scale. A similar phenomenon was also found in other colloidal systems [50]. 


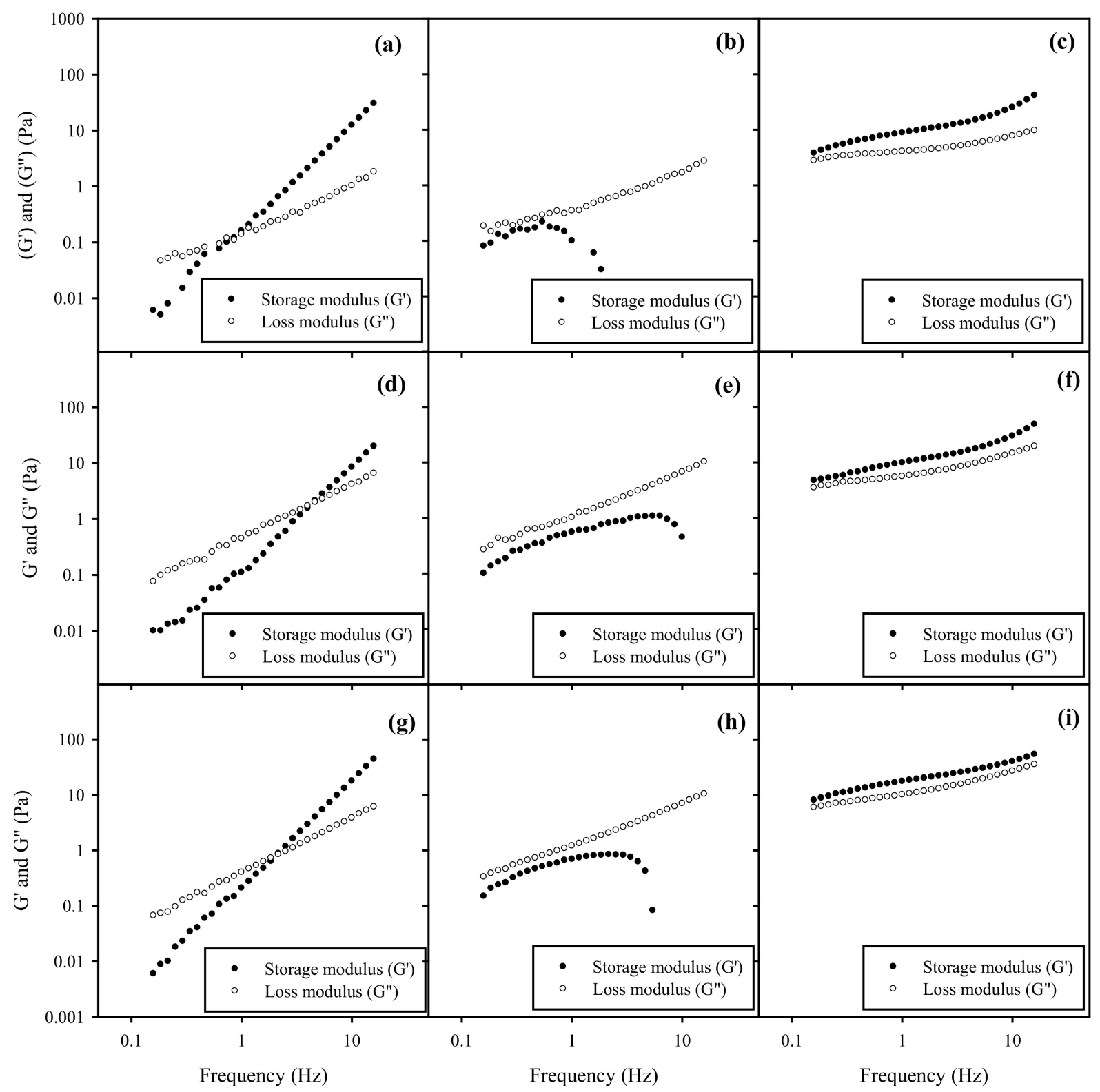

Figure 6. Frequency sweep on storage modulus $\bullet\left(\mathrm{G}^{\prime}\right)$ and loss modulus $\bigcirc\left(\mathrm{G}^{\prime \prime}\right)$ of BSFL oil NEs with SOR 30\% and HL/TPGS ratios for (a) 0/100, (b) 50/50, (c) 100/0 in the 3\% HA gel. G' and G" of BSFL oil NEs with SOR 30\% and HL/TPGS ratios for (d) 0/100, (e) 50/50, and (f) 100/0 in the 6\% HA gel. G' and G" of BSFL oil NEs with SOR $60 \%$ for (g) 0/100, (h) 50/50, and (i) 100/0 in the 6\% HA gel. 


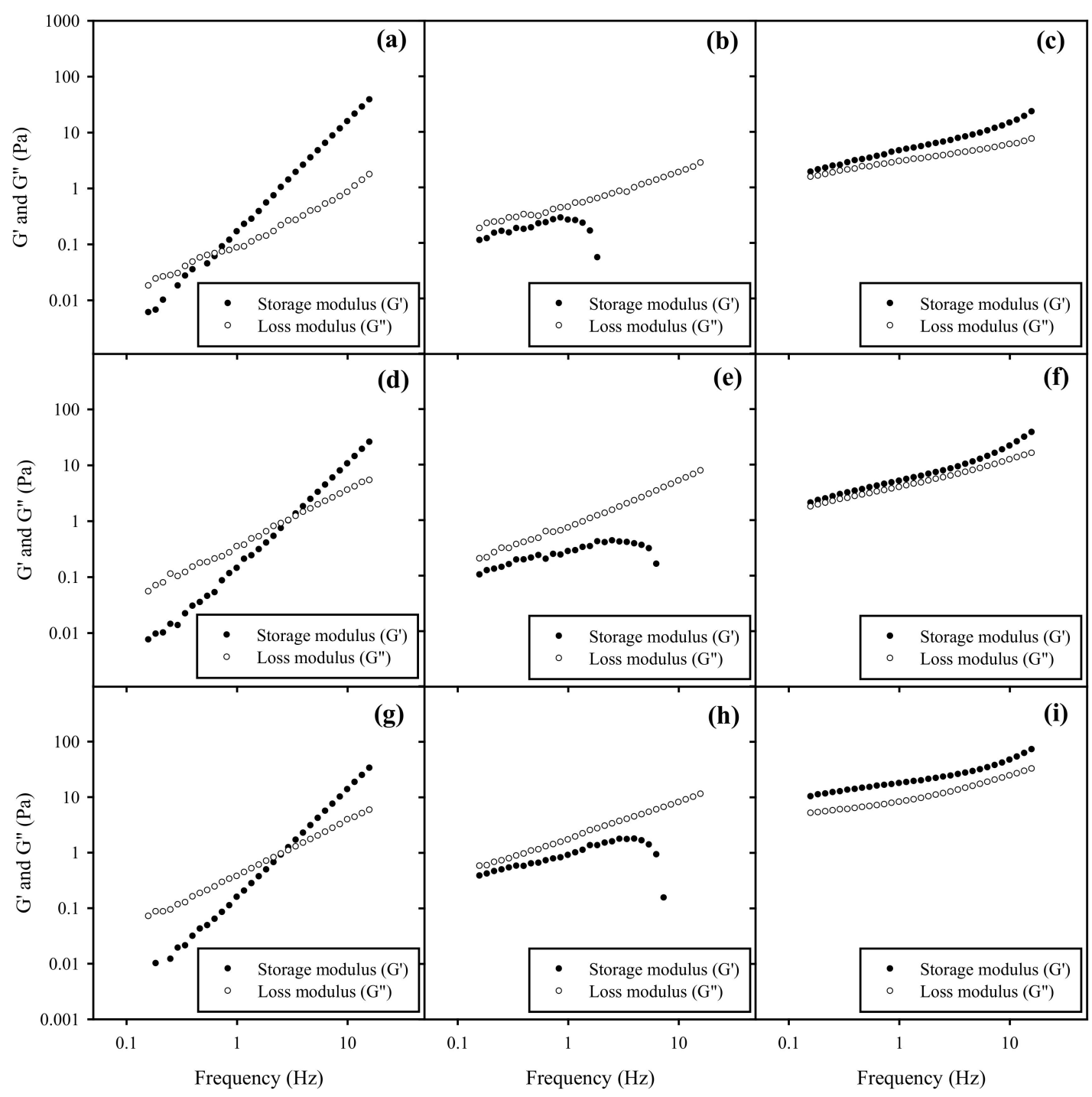

Figure 7. Frequency sweep on storage modulus $\bullet\left(G^{\prime}\right)$ and loss modulus $\bigcirc\left(G^{\prime \prime}\right)$ of AV oil NEs with SOR 30\% and HL/TPGS ratios for (a) 0/100, (b) 50/50, (c) 100/0 in the 3\% HA gel. G' and G" of AV oil NEs with SOR 30\% and HL/TPGS ratios for (d) 0/100, (e) 50/50, and (f) 100/0 in the 6\% HA gel. G' and G" of AV oil NEs with SOR 60\% for (g) 0/100, (h) 50/50, and (i) $100 / 0$ in the $6 \%$ HA gel.

\section{Conclusions}

In the present study, Apig-loaded NEs with BSFL and AV oils as well as mixed HL/TPGS surfactants were successfully prepared by using pre-homogenization and ultrasonication methods. Apig was efficiently encapsulated into NEs. The particle size and peak area of phase transition of BSFL oil and AV oil NEs with pure HL can be effectively reduced with increasing TPGS amount. The chemical stability and antioxidant ability of Apig was significantly improved by incorporation with TPGS-BSFL oil and AV oil NEs. Addition amount of TPGS not only impacted the skin permeation behavior of NEs for Apig but also dominated rheological behavior of NEs-HA gel. In summary, this study can provide very useful information on the development of topical delivery systems for Apig.

Supplementary Materials: The following are available online at https: / www.mdpi.com/article/ 10.3390 / polym13071016/s1, Figure S1. The viscosity of fresh AV oil-NEs with SOR 30 and 60\%, oil content $1 \%$, and different surfactant ratios of HL to TPGS as a function of the shear rate at $25^{\circ} \mathrm{C}$; Figure S2. The viscosity of fresh BSFL oil-NEs with SOR 30 and $60 \%$, oil content $1 \%$, and different surfactant ratios of HL to TPGS as a function of the shear rate at $25{ }^{\circ} \mathrm{C}$. 
Author Contributions: Conceptualization, funding acquisition, and writing-review and editing, T.-H.C.; writing—original draft preparation, D.S.N.; formal analysis, J.-Y.C.; validation, Y.-S.C.; data curation, C.-H.L.; visualization, M.-J.D. All authors have read and agreed to the published version of the manuscript.

Funding: This work was found by Grants MOST 107-2218-E-224 -003, 108-2622-E-224 -019 -CC2, and 108-2218-E-224 -002 as well as the other grant NPUST-NYUST-NTUST-109-06.

Institutional Review Board Statement: Not applicable.

Informed Consent Statement: Not applicable.

Data Availability Statement: The data presented herein are available on request from the corresponding author.

Acknowledgments: This study is financially supported by the Ministry of Science and Technology in Taiwan through Grants 107-2218-E-224 -003, 108-2622-E-224 -019-CC2, and 108-2218-E-224 -002 as well as the other grant NPUST-NYUST-NTUST-109-06.

Conflicts of Interest: The authors declare that they have no conflict of interest.

\section{References}

1. Kowalska, I.; Adach, W.; Stochmal, A.; Olas, B. A comparison of the effects of apigenin and seven of its derivatives on selected biomarkers of oxidative stress and coagulation in vitro. Food Chem. Toxicol. 2020, 136, 111016. [CrossRef] [PubMed]

2. Yan, X.; Qi, M.; Li, P.; Zhan, Y.; Shao, H. Apigenin in cancer therapy: Anti-cancer effects and mechanisms of action. Cell Biosci. 2017, 7, 50. [CrossRef]

3. Shukla, R.; Kashaw, S.K.; Jain, A.P.; Lodhi, S. Fabrication of Apigenin loaded gellan gum-chitosan hydrogels (GGCH-HGs) for effective diabetic wound healing. Int. J. Biol. Macromol. 2016, 91, 1110-1119. [CrossRef] [PubMed]

4. Das, S.; Das, J.; Paul, A.; Samadder, A.; Khuda-Bukhsh, A.R. Apigenin, a bioactive flavonoid from Lycopodium clavatum, stimulates nucleotide excision repair genes to protect skin keratinocytes from ultraviolet B-induced reactive oxygen species and DNA damage. J. Acupunct. Meridian Stud. 2013, 6, 252-262. [CrossRef] [PubMed]

5. Zhang, J.; Liu, D.; Huang, Y.; Gao, Y.; Qian, S. Biopharmaceutics classification and intestinal absorption study of apigenin. Int. J. Pharm. 2012, 436, 311-317. [CrossRef] [PubMed]

6. Shen, L.-N.; Zhang, Y.-T.; Wang, Q.; Xu, L.; Feng, N.-P. Enhanced in vitro and in vivo skin deposition of apigenin delivered using ethosomes. Int. J. Pharm. 2014, 460, 280-288. [CrossRef]

7. Al Shaal, L.; Shegokar, R.; Müller, R.H. Production and characterization of antioxidant apigenin nanocrystals as a novel UV skin protective formulation. Int. J. Pharm. 2011, 420, 133-140. [CrossRef]

8. Sen, K.; Banerjee, S.; Mandal, M. Dual drug loaded liposome bearing apigenin and 5-Fluorouracil for synergistic therapeutic efficacy in colorectal cancer. Colloids Surf. B Biointerfaces 2019, 180, 9-22. [CrossRef]

9. Abcha, I.; Souilem, S.; Neves, M.A.; Wang, Z.; Nefatti, M.; Isoda, H.; Nakajima, M. Ethyl oleate food-grade O/W emulsions loaded with apigenin: Insights to their formulation characteristics and physico-chemical stability. Food Res. Int. 2019, 116, 953-962. [CrossRef]

10. Shah, S.; Dhawan, V.; Holm, R.; Nagarsenker, M.S.; Perrie, Y. Liposomes: Advancements and innovation in the manufacturing process. Adv. Drug Deliv. Rev. 2020, 154, 102-122. [CrossRef]

11. Gamal, F.A.; Kharshoum, R.M.; Sayed, O.M.; El-Ela, F.I.A.; Salem, H.F. Control of basal cell carcinoma via positively charged ethosomes of Vismodegib: In vitro and in vivo studies. J. Drug Deliv. Sci. Technol. 2020, 56, 101556. [CrossRef]

12. Pool, H.; Mendoza, S.; Xiao, H.; McClements, D.J. Encapsulation and release of hydrophobic bioactive components in nanoemulsion-based delivery systems: Impact of physical form on quercetin bioaccessibility. Food Funct. 2013, 4, 162-174. [CrossRef] [PubMed]

13. Bhushani, J.A.; Karthik, P.; Anandharamakrishnan, C. Nanoemulsion based delivery system for improved bioaccessibility and Caco-2 cell monolayer permeability of green tea catechins. Food Hydrocoll. 2016, 56, 372-382. [CrossRef]

14. Qian, C.; Decker, E.A.; Xiao, H.; McClements, D.J. Nanoemulsion delivery systems: Influence of carrier oil on $\beta$-carotene bioaccessibility. Food Chem. 2012, 135, 1440-1447. [CrossRef] [PubMed]

15. Shi, Y.; Li, H.; Li, J.; Zhi, D.; Zhang, X.; Liu, H.; Wang, H.; Li, H. Development, optimization and evaluation of emodin loaded nanoemulsion prepared by ultrasonic emulsification. J. Drug Deliv. Sci. Technol. 2015, 27, 46-55. [CrossRef]

16. Hamed, R.; Basil, M.; AlBaraghthi, T.; Sunoqrot, S.; Tarawneh, O. Nanoemulsion-based gel formulation of diclofenac diethylamine: Design, optimization, rheological behavior and in vitro diffusion studies. Pharm. Dev. Technol. 2016, 21, 980-989. [CrossRef]

17. Kaur, A.; Katiyar, S.S.; Kushwah, V.; Jain, S. Nanoemulsion loaded gel for topical co-delivery of clobitasol propionate and calcipotriol in psoriasis. Nanomed. Nanotechnol. Biol. Med. 2017, 13, 1473-1482. [CrossRef]

18. Walia, N.; Dasgupta, N.; Ranjan, S.; Chen, L.; Ramalingam, C. Fish oil based vitamin D nanoencapsulation by ultrasonication and bioaccessibility analysis in simulated gastro-intestinal tract. Ultrason. Sonochem. 2017, 39, 623-635. [CrossRef] 
19. Chou, T.-H.; Nugroho, D.S.; Liang, C.-H. Effect of Mixed Emulsifier on the Physicochemical Properties of Avocado Oil Nanoemulsions. Int. J. Chem. Eng. Appl. 2020, 11. [CrossRef]

20. Chou, T.H.; Nugroho, D.S.; Cheng, Y.S.; Chang, J.Y. Development and characterization of nano-emulsions based on oil extracted from black soldier fly larvae. Appl. Biochem. Biotechnol. 2020, 191, 331-345. [CrossRef]

21. Ewald, N.; Vidakovic, A.; Langeland, M.; Kiessling, A.; Sampels, S.; Lalander, C.J.W.M. Fatty acid composition of black soldier fly larvae (Hermetia illucens)-Possibilities and limitations for modification through diet. Waste Manag. 2020, 102, 40-47. [CrossRef]

22. Lin, T.-K.; Zhong, L.; Santiago, J.L. Anti-inflammatory and skin barrier repair effects of topical application of some plant oils. Int. J. Mol. Sci. 2018, 19, 70. [CrossRef]

23. Wang, L.; Tabor, R.; Eastoe, J.; Li, X.; Heenan, R.K.; Dong, J. Formation and stability of nanoemulsions with mixed ionic-nonionic surfactants. Phys. Chem. Chem. Phys. 2009, 11, 9772-9778. [CrossRef] [PubMed]

24. Wei, J.; Huang, G.; Zhu, L.; Zhao, S.; An, C.; Fan, Y. Enhanced aqueous solubility of naphthalene and pyrene by binary and ternary Gemini cationic and conventional nonionic surfactants. Chemosphere 2012, 89, 1347-1353. [CrossRef]

25. Gorain, B.; Choudhury, H.; Pandey, M.; Kesharwani, P. Paclitaxel loaded vitamin E-TPGS nanoparticles for cancer therapy. Mater Sci. Eng. C 2018, 91, 868-880. [CrossRef] [PubMed]

26. Alkholief, M.; Albasit, H.; Alhowyan, A.; Alshehri, S.; Raish, M.; Kalam, M.A.; Alshamsan, A. Employing a PLGA-TPGS based nanoparticle to improve the ocular delivery of Acyclovir. Saudi Pharm. J. 2019, 27, 10. [CrossRef] [PubMed]

27. Daood, U.; Matinlinna, J.; Fawzy, A. Synergistic effects of VE-TPGS and riboflavin in crosslinking of dentine. Dent. Mater. 2019, 35, 356-367. [CrossRef]

28. Bae, D.-H.; Shin, J.-S.; Jin, F.-L.; Shin, G.-S.; Park, S.-J. Effect of hydrogenated lecithin on cytotoxicity of liposome. Bull. Korean Chem. Soc. 2009, 30, 339-342.

29. List, G. Soybean lecithin: Food, industrial uses, and other applications. In Polar Lipids; Elsevier: Amsterdam, The Netherlands, 2015; pp. 1-33.

30. Baldino, L.; Cardea, S.; Scognamiglio, M.; Reverchon, E. A new tool to produce alginate-based aerogels for medical applications, by supercritical gel drying. J. Supercrit. Fluids 2019, 146, 152-158. [CrossRef]

31. Diez-Sales, O.; Garrigues, T.; Herraez, J.; Belda, R.; Martin-Villodre, A.; Herraez, M. In vitro percutaneous penetration of acyclovir from solvent systems and Carbopol 971-P hydrogels: Influence of propylene glycol. J. Pharm. Sci. 2005, 94, 1039-1047. [CrossRef]

32. Xie, J.; Ji, Y.; Xue, W.; Ma, D.; Hu, Y. Hyaluronic acid-containing ethosomes as a potential carrier for transdermal drug delivery. Colloids Surf. B Biointerfaces 2018, 172, 323-329. [CrossRef] [PubMed]

33. Prajapati, S.K.; Jain, A.; Shrivastava, C.; Jain, A.K. Hyaluronic acid conjugated multi-walled carbon nanotubes for colon cancer targeting. Int. J. Biol. Macromol. 2019, 123, 691-703. [CrossRef]

34. Gao, Y.; Cheng, X.; Wang, Z.; Wang, J.; Gao, T.; Li, P.; Kong, M.; Chen, X. Transdermal delivery of 10, 11-methylenedioxycamptothecin by hyaluronic acid based nanoemulsion for inhibition of keloid fibroblast. Carbohydr. Polym. 2014, 112, 376-386. [CrossRef] [PubMed]

35. Li, C.; Liu, C.; Liu, J.; Fang, L. Correlation between rheological properties, in vitro release, and percutaneous permeation of tetrahydropalmatine. Aaps Pharmscitech 2011, 12, 1002-1010. [CrossRef] [PubMed]

36. Shen, P.-T.; Chiu, S.-W.; Chang, J.-Y.; Chung, T.-W.; Liang, C.-H.; Deng, M.-J.; Chou, T.-H. Formation and characterization of hydrogenated soybean lecithin/TPGS nano-dispersions as a potential carrier for active herbal agents. Colloids Surf. A Physicochem. Eng. Aspects 2021, 611, 125796. [CrossRef]

37. Atanase, L.I.; Riess, G. Stabilization of non-aqueous emulsions by poly (2-vinylpyridine)-b-poly (butadiene) block copolymers. Colloids Surf. A Physicochem. Eng. Aspects 2014, 458, 19-24. [CrossRef]

38. Atanase, L.I.; Riess, G. Block copolymer stabilized nonaqueous biocompatible sub-micron emulsions for topical applications. Int. J. Pharm. 2013, 448, 339-345. [CrossRef]

39. Djerdjev, A.M.; Beattie, J.K. Enhancement of ostwald ripening by depletion flocculation. Langmuir 2008, 24, 7711-7717. [CrossRef]

40. McClements, D.J. Protein-stabilized emulsions. Curr. Opin. Colloid Interface Sci. 2004, 9, 305-313. [CrossRef]

41. Sun, C.; Li, W.; Ma, P.; Li, Y.; Zhu, Y.; Zhang, H.; Adu-Frimpong, M.; Deng, W.; Yu, J.; Xu, X. Development of TPGS/F127/F68 mixed polymeric micelles: Enhanced oral bioavailability and hepatoprotection of syringic acid against carbon tetrachlorideinduced hepatotoxicity. Food Chem. Toxicol. 2020, 137, 111126. [CrossRef]

42. Lu, X.; Zhu, W.; Chen, T.; Peng, Q.; Yu, C.; Yang, M. Exploration of photophysical and photochemical properties of Zinc phthalocyanine-loaded SDC/TPGS mixed micelles. Chem. Phys. Lett. 2019, 735, 136737. [CrossRef]

43. Mahajan, H.S.; Patil, P.H. Central Composite Design-Based Optimization of Lopinavir Vitamin E-TPGS Micelle: In Vitro Characterization and In Vivo Pharmacokinetic Study. Colloids Surf. B Biointerfaces 2020, 194, 111149. [CrossRef] [PubMed]

44. Li, D.; Li, L.; Xiao, N.; Li, M.; Xie, X. Physical properties of oil-in-water nanoemulsions stabilized by OSA-modified starch for the encapsulation of lycopene. Colloids Surf. A Physicochem. Eng. Asp. 2018, 552, 59-66. [CrossRef]

45. Li, X.; Wang, L.; Wang, B. Optimization of encapsulation efficiency and average particle size of Hohenbuehelia serotina polysaccharides nanoemulsions using response surface methodology. Food Chem. 2017, 229, 479-486. [CrossRef] [PubMed]

46. Chen, Y.; Zhang, R.; Xie, B.; Sun, Z.; McClements, D.J. Lotus seedpod proanthocyanidin-whey protein complexes: Impact on physical and chemical stability of $\beta$-carotene-nanoemulsions. Food Res. Int. 2020, 127, 108738. [CrossRef] [PubMed]

47. Liu, J.; Jin, S.; Song, H.; Huang, K.; Li, S.; Guan, X.; Wang, Y. Effect of extrusion pretreatment on extraction, quality and antioxidant capacity of oat (Avena sativa L.) bran oil. J. Cereal Sci. 2020, 95, 102972. [CrossRef] 
48. Heuschkel, S.; Goebel, A.; Neubert, R.H. Microemulsions-modern colloidal carrier for dermal and transdermal drug delivery. J. Pharm. Sci. 2008, 97, 603-631. [CrossRef]

49. Štaka, I.; Cadete, A.; Surikutchi, B.T.; Abuzaid, H.; Bradshaw, T.D.; Alonso, M.J.; Marlow, M. A novel low molecular weight nanocomposite hydrogel formulation for intra-tumoural delivery of anti-cancer drugs. Int. J. Pharm. 2019, 565, 151-161. [CrossRef]

50. Lee, J.-H.; Gustin, J.P.; Chen, T.; Payne, G.F.; Raghavan, S.R. Vesicle-Biopolymer Gels: Networks of Surfactant Vesicles Connected by Associating Biopolymers. Langmuir 2005, 21, 26-33. [CrossRef] 